\title{
The Effect of High Glass Fiber Content and Reinforcement Combination on Pulse-Echo Ultrasonic Measurement of Composite Ship Structures
}

\author{
Sang-Gyu Lee $\left.{ }^{1} \mathbb{(}\right)$, Daekyun $\mathrm{Oh}^{2} \mathbb{C}$ and Jong Hun Woo $^{3, *}$ \\ 1 Department of Ocean System Engineering, Graduate School, Mokpo National Maritime University, \\ Mokpo 58628, Korea; lsg93630@gmail.com \\ 2 Department of Naval Architecture and Ocean Engineering, Mokpo National Maritime University, \\ Mokpo 58628, Korea; dkoh@mmu.ac.kr \\ 3 Department of Naval Architecture and Ocean Engineering, Seoul National University, Seoul 08826, Korea \\ * Correspondence: j.woo@snu.ac.kr; Tel.: +82-2-880-7330
}

Citation: Lee, S.-G.; Oh, D.; Woo, J.H The Effect of High Glass Fiber

Content and Reinforcement

Combination on Pulse-Echo

Ultrasonic Measurement of

Composite Ship Structures. J. Mar. Sci.

Eng. 2021, 9, 379. https://doi.org/

$10.3390 /$ jmse 9040379

Academic Editor: Dong-Sheng Jeng

Received: 28 January 2021

Accepted: 29 March 2021

Published: 2 April 2021

Publisher's Note: MDPI stays neutral with regard to jurisdictional claims in published maps and institutional affiliations.

Copyright: (c) 2021 by the authors. Licensee MDPI, Basel, Switzerland. This article is an open access article distributed under the terms and conditions of the Creative Commons Attribution (CC BY) license (https:// creativecommons.org/licenses/by/ $4.0 /)$.

\begin{abstract}
Ship structures made of glass fiber-reinforced polymer (GFRP) composite laminates are considerably thicker than aircraft and automobile structures and more likely to contain voids. The production characteristics of such composite laminates were investigated in this study by ultrasonic nondestructive evaluation (NDE). The laminate samples were produced from E-glass chopped strand mat (CSM) and woven roving (WR) fabrics with different glass fiber contents of 30-70\%. Approximately 300 pulse-echo ultrasonic A-scans were performed on each sample. The laminate samples produced from only CSM tended to contain more voids compared with those produced from a combination of CSM and WR, resulting in the relative density of the former being lower than the design value, particularly for high glass fiber contents of $\geq 50 \%$. The velocity of the ultrasonic waves through the CSM-only laminates was also lower for higher glass fiber contents, whereas it steadily increased for combined CSM-WR laminates. Burn-off tests of the laminates further revealed that the fabric configuration of the combined CSM-WR laminates was of higher quality, prevented the formation of voids, and improved inter-layer bonding. These findings indicate that combined CSM-WR laminates should be used to achieve more accurate ultrasonic NDE of GFRP composite structures.
\end{abstract}

Keywords: composite ship; glass fiber-reinforced polymer; nondestructive evaluation; ultrasonics; defect

\section{Introduction}

Glass fiber-reinforced polymer (GFRP) composites have been widely used for decades to build small ships, such as fishing boats, yachts, and patrol boats [1,2], owing to their suitable specific strength, corrosion resistance, and excellent workability [3].

Overall, considerable progress has been achieved in the marine application of tailored materials and optimal structural design technology. While life cycle issues, such as sustainability and environmental protection, have received greater attention in recent times, there is still an attitude of conservatism and hesitation in specifying the application of polymer composites as the solution to several relevant challenges [1]. With regard to the environment, studies have been conducted to optimize the laminates of composite structures [2,4]; however, the design margin remains relatively large because, for example, composite structures, such as ships, are usually built in small shipyards, and the inspection of the production quality does not tend to be sophisticated. Even pleasure and commercial boats that require a higher quality of production are not subjected to quality control and rely only on external surface quality assessment [5].

Nondestructive evaluation is one of the most commonly used quality evaluation methods and is widely applied to composites [6,7]. However, while it is widely employed 
in the aviation industry for quantitative defect detection and quality characterization of fiber-reinforced polymer (FRP) structures, it is not often applied to GFRPs used to produce ships owing to the much larger thickness of the GFRP structures and the limitations of the measurement environment. This challenge can be addressed by using pulse-echo ultrasonics, which is safe and reliable, enables inspection from only one side of a ship structure, and is convenient for use in a spatially limited environment owing to the portability of the utilized equipment $[8,9]$. Although pulse-echo ultrasonics can also be performed on aircraft for quantitative defect detection and quality characterization, it is more often used for damage repair or maintenance of GFRP ships [10]. This is because the GFRPs used in ships are generally produced by the hand lay-up method [11,12], which tends to unevenly, inadequately, or excessively distribute the polymer resins in the GFRP structure, resulting in more defects in the laminates, such as porosity, voids, and delamination. This causes inconsistency in the quality of the GFRP laminates and affects their performance and the results of ultrasonic nondestructive evaluation (NDE) [13].

Mouritz [13] investigated the strength effect of porosity in the GFRP composite structures of ships. His testing of highly porous, thick composites $(20-150 \mathrm{~mm})$ revealed that the shear strength decreased with increasing void content. Oh et al. [14] reported that an increase in the glass fiber content $\left(G_{\mathrm{c}}\right)$ of FRP hull plates caused a decrease in strength at a high impregnation ratio of $\geq 60 \%$ because of the poor quality of the FRP laminate. Through a comparative study of the void content of FRP hull plates, Han et al. [15] observed a relatively high void volume in high- $G_{\mathrm{c}}$ laminates and verified the results by burn-off tests.

Additionally, the combination of different reinforcements in GFRPs used for ship structures is not ideal for ultrasonic inspection. E-glass chopped strand mat (CSM) and woven roving (WR) fabrics are the main types of composite fabrics used to produce major ship structures, such as hulls and decks, and both fabrics can be used together. CSM can be exclusively used but is sometimes combined with WR, which has a higher weight per unit area and is interlaced to achieve directional strength characteristics and enhanced impact resistance [11], which are desirable for large structures. The combination of CSM and WR is also known to improve the interlaminar bonds and reduce porosity [5]. However, the enhanced strength of CSM-WR laminates can only be achieved through high-quality combination; otherwise, the combination itself may increase the number of voids [16-18] and cause inaccurate results of ultrasonic NDE testing.

To improve the structural characteristics of GFRP ships and the accuracy of ultrasonic $\mathrm{NDE}$, it is critical to properly set the receiver's pulse-echo velocity with respect to the relative density of the test specimen. In other words, it is important to understand the variation of the pulse-echo velocity of the laminates with the design $G_{c}$ when producing GFRP ship structures. Generally, the ultrasonic velocity increases with increasing density of a test specimen [19]. Although the relative density of GFRP structures is lower than that of steel, the irregularity of the crystalline particles of the former is greater, resulting in its greater scattering or absorption of ultrasonic waves [20]. In addition, the relative density of laminates varies with the $G_{\mathrm{c}}$ between the reinforcements and polyester, and this affects the number of defects, such as voids, making it more difficult to perform ultrasonic NDE [21].

In this study, the effect of the production characteristics of GFRP laminates used for ship construction on the NDE of ships was investigated. For this purpose, laminate specimens similar to the hull plates of GFRP ship structures were produced with normal $(30-50 \%)$ and high $(50-70 \%)$ values using the hand lay-up method for producing CSM and WR fabrics. The same design was used to produce combined CSM-WR specimens. The laminates were 4-6 $\mathrm{mm}$ thick and were examined by pulse-echo ultrasonic A-scanning, followed by vernier caliper measurements and accurate $G_{c}$ measurements through burnoff tests [15]. The A-scanning results were analyzed to understand the effects of the $G_{c}$ variation and combined reinforcements on the pulse-echo velocity and the effects of internal defects in the laminates, such as voids, on the ultrasonic waves. 


\section{Background}

\subsection{Pulse-Echo Ultrasonics}

Pulse-echo ultrasonics is an NDE method for determining the thickness of a test specimen and the location and size of defects in it by analyzing the pulse-echo velocity and the time taken by the ultrasonic wave generated from the probe to travel through the specimen from the front surface to the back surface, or to a defect in the specimen, and return (Figure 1) [9].
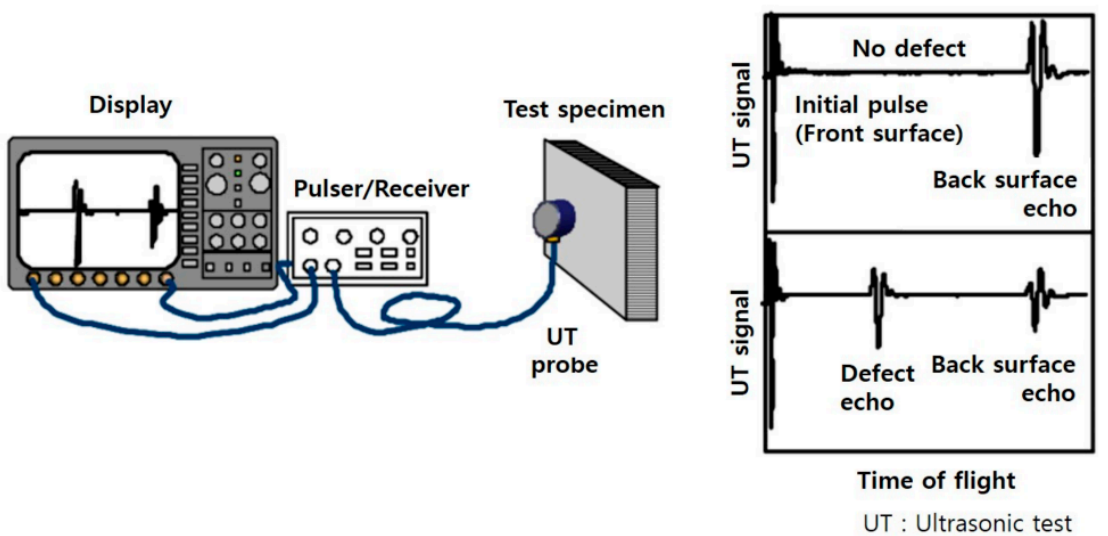

Figure 1. Example of pulse-echo ultrasonic testing; reprinted with permission from ref. [22]. 2009 Shant Kenderian.

For accurate measurement, it is crucial to properly set the transmission and reception conditions between the generation of the pulse by the probe and its reflection as a pulseecho. The relevant factors include pulse-echo velocity, which is highly dependent on the physical properties of the test specimen, such as density. The pulse-echo velocity $(C, \mathrm{~m} / \mathrm{s})$ is the speed at which the ultrasonic wave travels through the specimen and is determined by the density $\left(\rho, \mathrm{kg} / \mathrm{m}^{3}\right)$ and modulus of elasticity $\left(E, \mathrm{kgf} / \mathrm{mm}^{2}\right)$ of the specimen, as expressed by Equation (1) [23]. The reflection or transmission of an ultrasonic wave during the testing is controlled by the variation of the acoustic impedance $\left(\mathrm{Z}, \mathrm{kg} / \mathrm{m}^{2} \mathrm{~s}\right)$, which is an inherent property of the specimen material and can be obtained as the product of the specimen density and the pulse-echo velocity, as expressed by Equation (2) [23].

$$
C=(E / \rho)^{0.5}
$$

where $E$ is the modulus of elasticity of the test specimen in $\mathrm{kgf} / \mathrm{mm}^{2}$, and $\rho$ is the density of the test specimen in $\mathrm{kg} / \mathrm{m}^{3}$.

$$
Z=\rho \times C
$$

where $\rho$ is the density of the test specimen in $\mathrm{kg} / \mathrm{m}^{3}$, and $C$ is the pulse-echo velocity in $\mathrm{m} / \mathrm{s}$.

In the case of a single material, such as metal, the acoustic speed and acoustic impedance of the reflected wave corresponding to the representative material density [23] can be applied for testing. However, in the case of composites, such as GFRP, which consists of a mixture of E-glass fiber and polyester, NDE is more challenging [20]. The pulse-echo velocity of GFRP laminate specimens produced with the same glass fiber content $\left(G_{\mathrm{c}}\right)$ and relative density may differ owing to differences in production quality $[9,24]$. For high accuracy in ultrasonic NDE of GFRP composites, a low-frequency probe $(0.50-2.25 \mathrm{MHz})$ is recommended $[9,20]$. In addition, for application to the size scale of ship structures, the NDE method should be portable. Pulse-echo ultrasonics is recommended for this purpose because it requires measurement from only one side, which is particularly suitable for the shape of a ship hull [9]. 


\subsection{Effect of GFRP Laminate Quality on Ultrasonic NDE}

The pulse-echo velocity of the test specimen must be properly set for accurate thickness measurement in ultrasonic NDE. Even when the laminate structures are built with the same $G_{c}$, the error rate of the measurement increases with increasing thickness and the presence of defects, such as voids. The generation of voids also increases with increasing thickness of the composite laminate, thereby decreasing the strength of the laminate (Figure 2a) [14,25]. In addition, the ultrasonic attenuation increases with increasing void content (Figure 2b) $[8,13,24,26]$; that is, the ultrasonic wave attenuation of GFRP structures with the same $G_{\mathrm{c}}$ and thickness may also vary depending on the quality of the laminate. It is thus important to characterize the properties of GFRP composites for accurate ultrasonographic NDE.

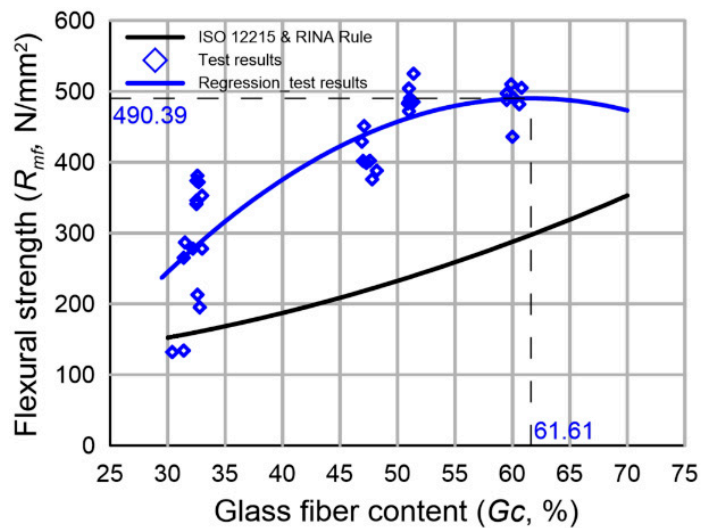

(a)

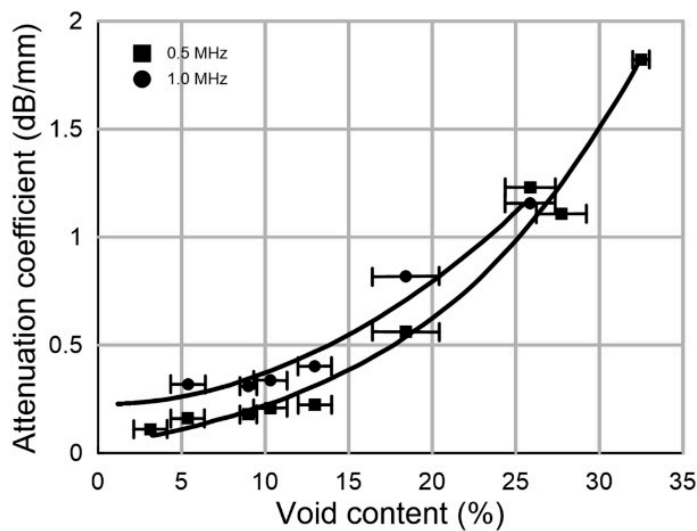

(b)

Figure 2. Laminate properties: (a) flexural strength with respect to the glass fiber content $\left(G_{\mathrm{C}}\right)$ [14] and (b) attenuation coefficient with respect to the void content; Reprinted with permission from ref. [13]. 2020 Daekyun Oh.

The hull specimens used in this study were prepared with the $G_{\mathrm{c}}$ values commonly used for the production of GFRP structures (30-50\%) and higher values of up to $70 \%$. This was used to examine the variation of the pulse-echo velocity of the ultrasonic wave with $G_{c}$. In addition, each specimen was burned off to measure the void volume and examine its correlation with $G_{\mathrm{c}}$.

\section{Experiments and Results}

\subsection{Design and Fabrication of GFRP Hull Plate}

The tested GFRP laminate specimens were prepared using E-glass fiber $450 \mathrm{~g} / \mathrm{m}^{2} \mathrm{CSM}$ and $570 \mathrm{~g} / \mathrm{m}^{2} \mathrm{WR}$ [27], which are widely used for the production of small fishing boats. Polyester with a density of $1.22 \mathrm{~g} / \mathrm{m}^{2}$ was used as the resin matrix [28]. The specimens were produced by varying $G_{\mathrm{c}}$ from $30 \%$ to $70 \%$ and also by combining CSM and WR. The designs of the GFRP laminate specimens are illustrated in Figures 3 and 4. The design thickness $\left(T_{\text {design }}\right)$ values of the specimens ranged between 4.14 and $5.15 \mathrm{~mm}$ (Tables 1 and 2), which are similar to those of mass-produced hull plates of small fishing boats weighing 3-7 gross tons $(\mathrm{G} / \mathrm{T})$.

The laminates were produced by the hand lay-up method, and their thickness was measured by ultrasonics and a vernier caliper; they were then cut into pieces measuring $30 \times 30 \mathrm{~mm}$ for burn-off testing. There were $44 \mathrm{CSM}$-only specimens, divided into four equal groups with $G_{\mathrm{C}}$ values of $30 \%, 40 \%, 50 \%$, and $60 \%$, respectively, and 44 combined CSM-WR specimens, similarly divided into four equal groups with $G_{\mathrm{c}}$ values of $33 \%, 44 \%$, $54 \%$, and $65 \%$, respectively.

The thicknesses of both the single-material and combined-material specimens were measured using a vernier caliper at five locations, namely the center and four corners. Burn-off tests were conducted on seven single-material and seven combined-material specimens to measure the actual $G_{\mathrm{c}}$ values. Figures $5 \mathrm{a}$ and $6 \mathrm{a}$ show the specimens, and 
Figures $5 \mathrm{~b}$ and $6 \mathrm{~b}$ compare the thicknesses measured by the vernier calipers with their design thicknesses.

Glass fiber content $30 \%$ (Chopped strand mat) $\times 5$ 5-ply

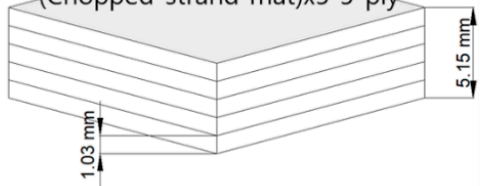

Glass fiber content $50 \%$ (Chopped strand mat) $\times 9$ 9-ply

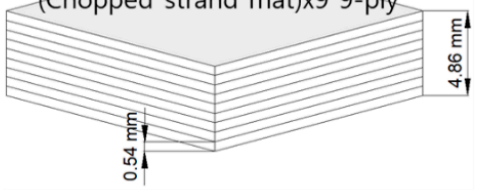

Glass fiber content $40 \%$

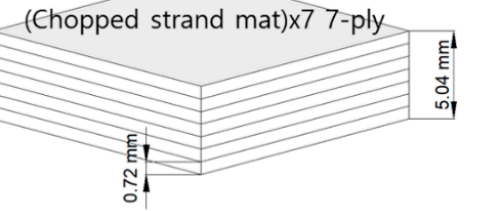

Glass fiber content $60 \%$ (Chopped strand mat)x12 12-ply

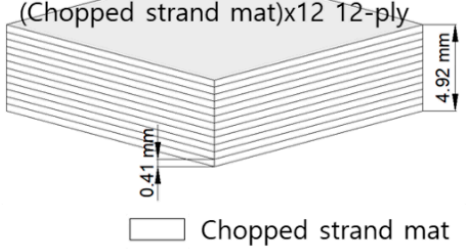

Figure 3. Designs of single-material specimens produced using chopped strand mat.

Glass fiber content 33\% (Chopped strand mat+Woven roving) $\times 2$ 4-ply

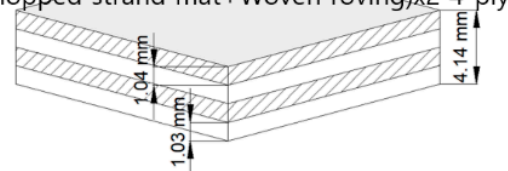

Glass fiber content $54 \%$ (Chopped strand mat+Woven roving) $\times 4$ 8-ply

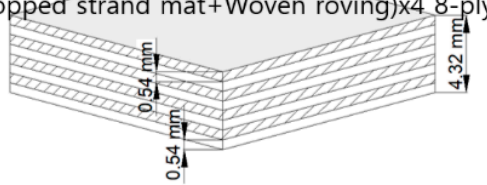

Glass fiber content $44 \%$

(Chopped strand mat+Woven roving)x3 6-ply

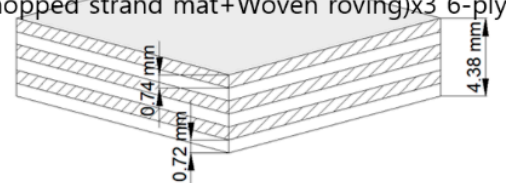

Glass fiber content $65 \%$

(Chopped strand mat+Woven roving) $\times 5$ 10-ply

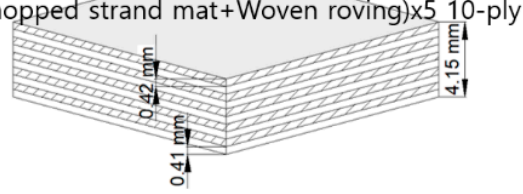

Chopped strand mat $V / 7 /$ Woven roving

Figure 4. Designs of combined-material specimens produced using chopped strand mat and woven roving.

Table 1. Design details of single-material specimens.

\begin{tabular}{ccccc}
\hline Design $G_{\mathbf{c}}(\mathbf{\%})$ & Laminate Schedule & No. of Plies (ply) & $T_{\text {single }}(\mathbf{m m})$ & $T_{\text {design }}(\mathbf{m m})$ \\
\hline 30.00 & CSM $\times 5$ & 5 & 1.03 & 5.15 \\
40.00 & CSM $\times 7$ & 7 & 0.72 & 5.04 \\
50.00 & CSM $\times 9$ & 9 & 0.54 & 4.86 \\
60.00 & CSM $\times 12$ & 12 & 0.41 & 4.92 \\
\hline
\end{tabular}

Table 2. Design details of combined-material specimens.

\begin{tabular}{cccccc}
\hline \multirow{2}{*}{ Design $G_{\mathbf{c}}(\%)$} & Laminate Schedule & No. of Plies (ply) & \multicolumn{2}{c}{$\boldsymbol{T}_{\text {single }}(\mathbf{m m})$} & \multirow{2}{*}{$\boldsymbol{T}_{\text {design }}$ (mm) } \\
\cline { 4 - 5 } & & & $\mathbf{C S M}$ & WR & \\
\hline 33.00 & $(\mathrm{CSM}+\mathrm{WR}) \times 2$ & 4 & 1.03 & 1.04 & 4.14 \\
44.00 & $(\mathrm{CSM}+\mathrm{WR}) \times 3$ & 8 & 0.72 & 0.74 & 4.38 \\
54.00 & $(\mathrm{CSM}+\mathrm{WR}) \times 4$ & 10 & 0.54 & 0.54 & 4.32 \\
65.00 & $(\mathrm{CSM}+\mathrm{WR}) \times 5$ & 0.41 & 0.42 & 4.15 \\
\hline
\end{tabular}

\subsection{Void Volume Determined by Burn-Off Test}

To ensure that the specimens were produced according to the design $G_{c}$, burn-off tests were conducted on seven single-material specimens and seven combined-material specimens. Based on ASTM D3171 [29], the furnace was heated to approximately $600{ }^{\circ} \mathrm{C}$, and the specimens were burned for $2 \mathrm{~h}$ and $30 \mathrm{~min}$. The specimens were subsequently 
cooled and repeatedly weighed until the weight change was within $0.001 \mathrm{~g}$. This was followed by calcination of the polyester in the specimens and determination of the weight of the remaining E-glass fiber. The $G_{c}$ of each specimen was calculated using Equation (3) [29], while the internal void volume was calculated using Equation (4). Tables 3-6 compare the design and analytically determined $G_{\mathrm{c}}(\%)$ and void volume $\left(V_{\mathrm{V}}, \%\right)$ values of the single-material and combined-material specimens.

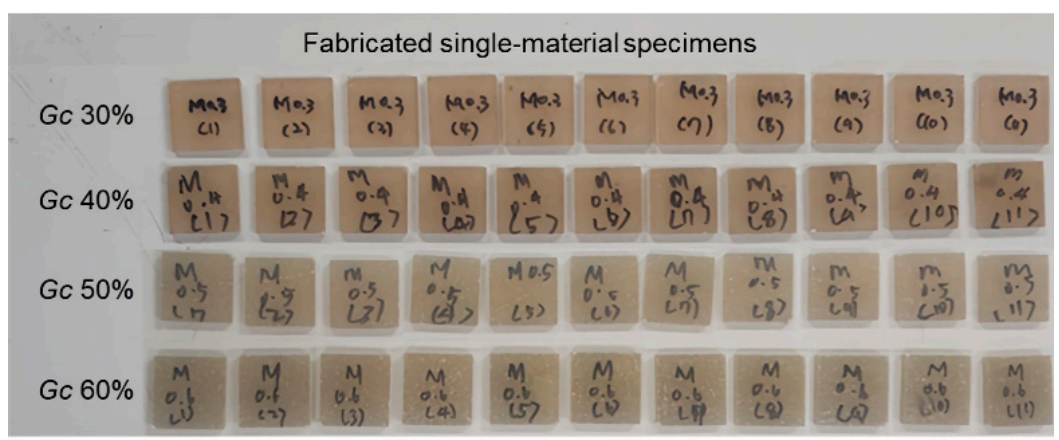

(a)

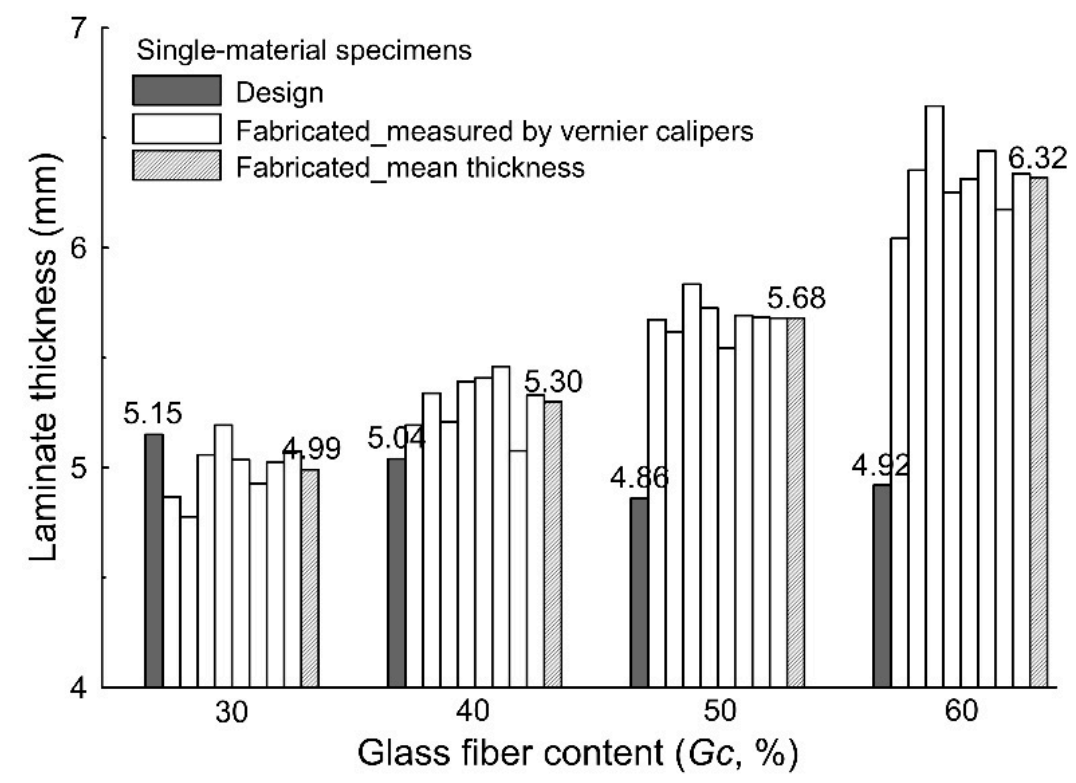

(b)

Figure 5. Single-material specimens: (a) produced specimens; (b) measured thickness.

$$
\begin{gathered}
G_{\mathrm{c}}=M_{\mathrm{f}} / M_{\mathrm{i}} \times 100 \\
V_{\mathrm{V}}=\left(1-M_{\mathrm{f}} / M_{\mathrm{i}} \times \rho_{\mathrm{c}} / \rho_{\mathrm{f}}-\left(M_{\mathrm{i}}-M_{\mathrm{f}}\right) / M_{\mathrm{i}} \times \rho_{\mathrm{c}} / \rho_{\mathrm{r}}\right) \times 100
\end{gathered}
$$

where $M_{\mathrm{i}}$ and $M_{\mathrm{f}}$ are, respectively, the weights of the specimen before and after calcination $(\mathrm{g}) ; \rho_{\mathrm{f}}$ is the density of the glass fiber $\left(\mathrm{g} / \mathrm{cm}^{3}\right)$; and $\rho_{\mathrm{r}}$ is the density of the resin matrix $\left(\mathrm{g} / \mathrm{cm}^{3}\right)$.

\begin{tabular}{|c|c|c|c|c|c|c|c|c|}
\hline Design $G_{c}(\%)$ & & & Test & lue of & $c(\%)$ & & & Mean (\%) \\
\hline 30.00 & 32.09 & 33.14 & 33.58 & 34.42 & 32.39 & & & 32.93 \\
\hline 40.00 & 40.55 & 39.34 & 39.41 & 39.94 & 38.85 & & & 39.62 \\
\hline 50.00 & 46.95 & 46.65 & 46.11 & 45.66 & 45.34 & & & 46.14 \\
\hline 60.00 & 50.80 & 51.16 & 52.12 & 51.72 & 52.50 & 53.36 & 51.82 & 51.93 \\
\hline
\end{tabular}

Table 3. $G_{C}$ values of the single-material specimens determined by burn-off tests. 


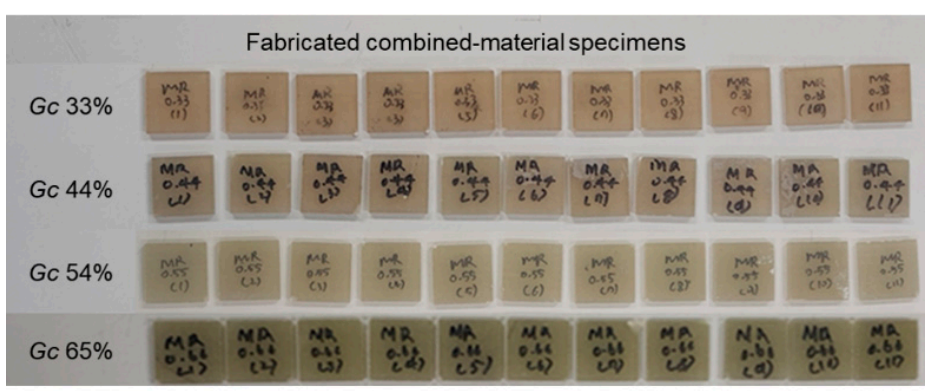

(a)

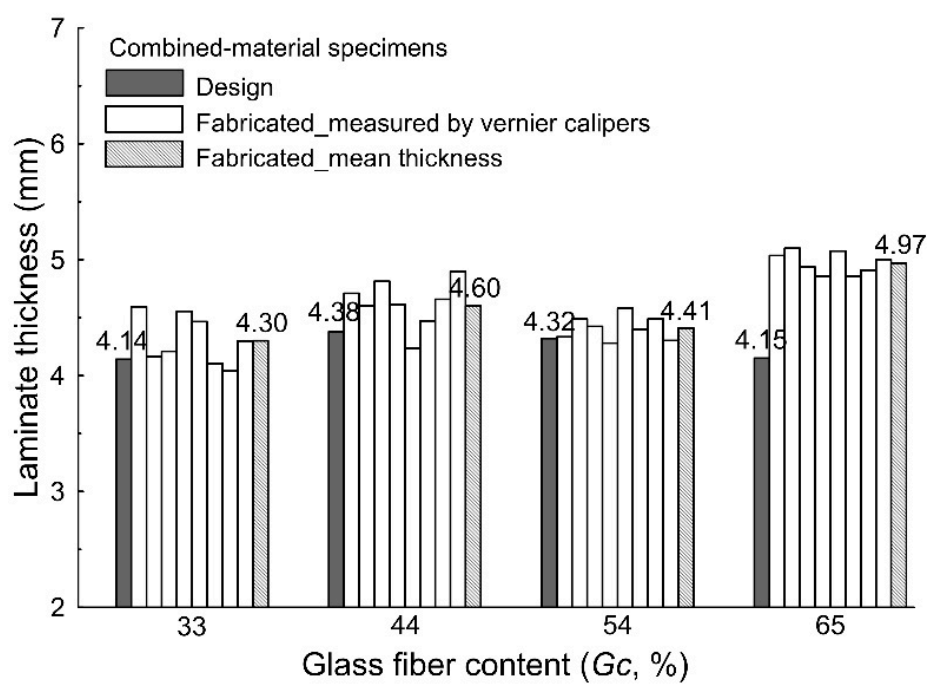

(b)

Figure 6. Combined-material specimens: (a) produced specimens; (b) measured thickness.

Table 4. $V_{\mathrm{V}}$ values of the single-material specimens determined by burn-off tests.

\begin{tabular}{|c|c|c|c|c|c|c|c|c|}
\hline Design $G_{c}(\%)$ & & & Test & lue of & $(\%)$ & & & Mean (\%) \\
\hline 30.00 & 1.53 & 1.52 & 1.13 & 1.70 & 1.72 & & & 1.52 \\
\hline 40.00 & 1.76 & 1.60 & 1.66 & 2.00 & 1.93 & & & 1.79 \\
\hline 50.00 & 1.76 & 2.16 & 1.78 & 2.09 & 1.87 & & & 1.93 \\
\hline 60.00 & 2.06 & 2.92 & 3.60 & 2.73 & 3.88 & 5.07 & 3.39 & 3.38 \\
\hline
\end{tabular}

Table 5. Gc values of the combined-material specimens determined by burn-off tests.

\begin{tabular}{|c|c|c|c|c|c|c|c|c|}
\hline Design $G_{c}(\%)$ & & & Test & lue of & $c(\%)$ & & & Mean (\%) \\
\hline 33.00 & 35.31 & 34.82 & 33.05 & 35.98 & 32.59 & & & 34.35 \\
\hline 44.00 & 43.62 & 43.31 & 44.00 & 44.12 & 45.30 & & & 44.07 \\
\hline 54.00 & 53.99 & 55.48 & 53.62 & 52.75 & 54.77 & & & 54.12 \\
\hline 65.00 & 61.24 & 59.69 & 60.25 & 60.12 & 60.53 & 61.71 & 60.36 & 60.56 \\
\hline
\end{tabular}

Table 6. $V_{\mathrm{V}}$ values of the combined-material specimens determined by burn-off tests.

\begin{tabular}{|c|c|c|c|c|c|c|c|c|}
\hline \multirow{2}{*}{$\frac{\text { Design } G_{\mathrm{c}}(\mathbf{\%})}{33.00}$} & \multicolumn{7}{|c|}{ Test Value of $V_{V}(\%)$} & \multirow{2}{*}{$\frac{\text { Mean }(\%)}{1.36}$} \\
\hline & 1.58 & 1.26 & 1.46 & 1.35 & 1.17 & & & \\
\hline 44.00 & 1.31 & 1.72 & 1.57 & 1.65 & 1.84 & & & 1.62 \\
\hline 54.00 & 2.02 & 1.96 & 2.34 & 2.29 & 2.02 & & & 2.13 \\
\hline 65.00 & 3.50 & 2.31 & 2.74 & 3.20 & 2.95 & 3.86 & 3.38 & 3.13 \\
\hline
\end{tabular}

The burn-off test results showed that the single-material specimens had void contents of $1.13-5.07 \%$ (Table 4 ), while the values for the combined-material specimens were within 
$1.17-3.86 \%$ (Table 6). This indicates that the specimens were properly produced with the average void content of typical GFRP laminates [30].

\subsection{Variation of Pulse-Echo Velocity with Glass Fiber Content}

CMX DL+ (Dakota Ultrasonics) [31] was used for the pulse-echo ultrasonic measurements, with a $1 \mathrm{MHz}$ ultrasonic wave of diameter $12.7 \mathrm{~mm}$ generated for the A-scan of the specimens. Figure 7 shows the pulse-echo velocity at which the thickness of the specimen measured by a vernier caliper matches that determined by ultrasonic measurement with respect to the $G_{\mathrm{c}}$ value determined by burn-off tests.

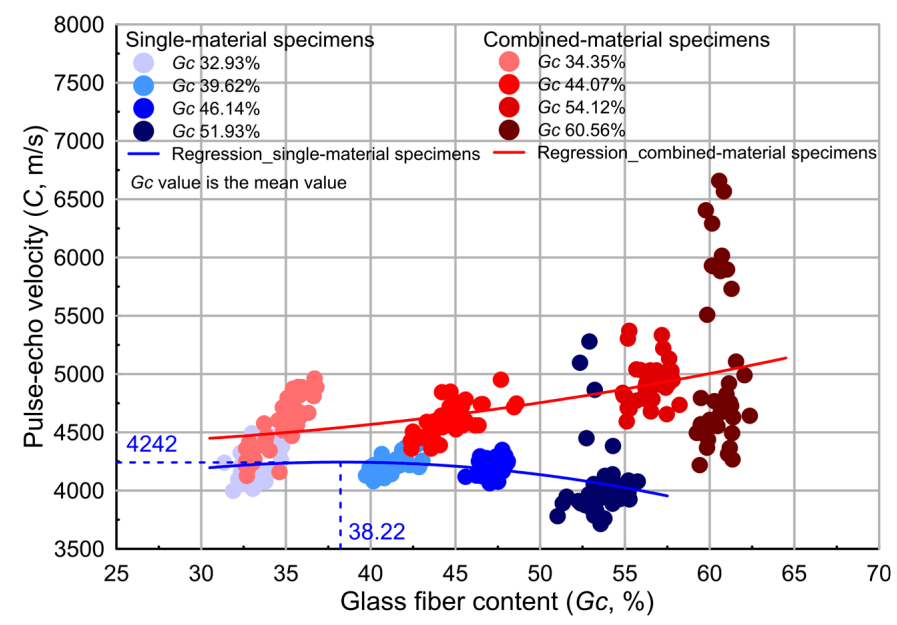

Figure 7. Variation of pulse-echo velocity with $G_{C}$.

As can be observed from Figure 7, the pulse-echo velocity of the single-material specimens tended to slightly increase with increasing $G_{\mathrm{c}}$ up to $38.22 \%$, after which it began to decrease. Conversely, that of the combined-material specimens continuously increased with a large spread occurring beyond a $G_{c}$ of $60.56 \%$. The distribution of the pulse-echo velocity for the single-material specimens was also found to spread beyond a $G_{c}$ of $51.93 \%$. These observations can be attributed to the defects in the laminate, such as delamination, debonding, and pulling of the polyester due to uneven impregnation. Figure 8 shows the defects observed in some example specimens.
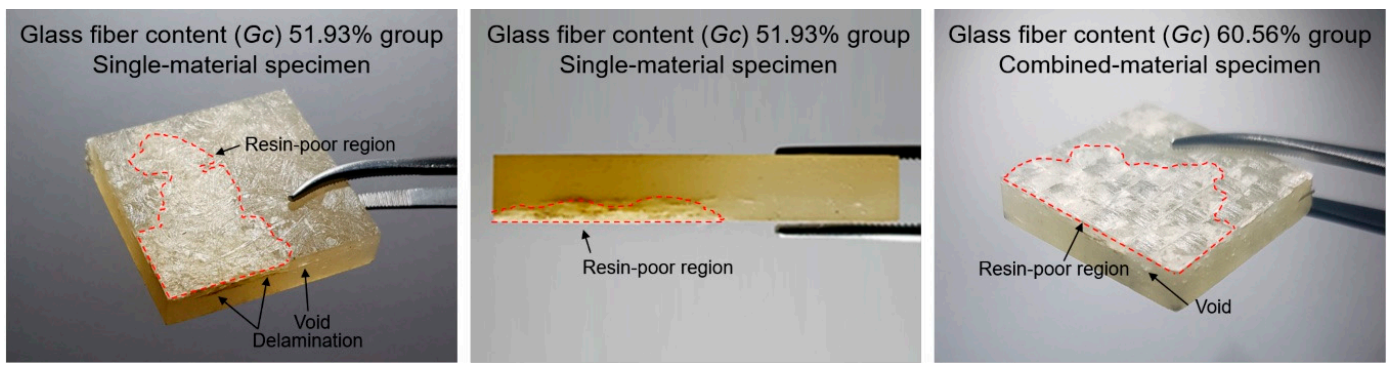

Figure 8. Defects in some example specimens.

\section{Discussion}

The change in the pulse-echo velocity of the single-material specimens with increasing glass fiber content $\left(G_{\mathrm{c}}\right)$ was negligible, with the velocity decreasing as $G_{\mathrm{c}}$ further increased above $38.22 \%$. Continuous increase in the velocity was observed for the combined-material specimens even for $G_{C}$ values above $50 \%$. While the relative density and ultrasonic velocity for laminates generally tend to increase with increasing E-glass fiber content [13,19], the tendency was different for the single-material specimens. However, we observed increased data spread in the high- $G_{c}$ region for both types of specimens. It is believed that the density 
of the laminates did not actually increase normally with increasing void volume after a certain point in $G_{c}$, and that the internal voids also impeded the ultrasonic wave.

Figure 9 shows the void volume contents of the two types of laminate specimens determined by burn-off tests and the variation of the actual relative density calculated from the void volume. The single-material and combined-material specimens exhibited increases in their void volume with $G_{\mathrm{c}}$ exceeding approximately $37.74 \%$ and $38.18 \%$, respectively (Figure 9a). However, the increase in the single-material specimens was larger than that in the combined-material specimens. The difference was more evident beyond $G_{c}$ values of $45-50 \%$, with the void volume reaching as high as $5.07 \%$ (Figure $9 \mathrm{a}$ ). This increase in void volume with increasing $G_{\mathrm{c}}$ caused a reduction in the increase in the actual relative density (Figure 9b), resulting in defects, such as voids, inside the laminates. The defects impeded the transmission of ultrasonic waves and decreased the ultrasonic measurement accuracy, with significant effects on the laminate density and pulse-echo velocity.

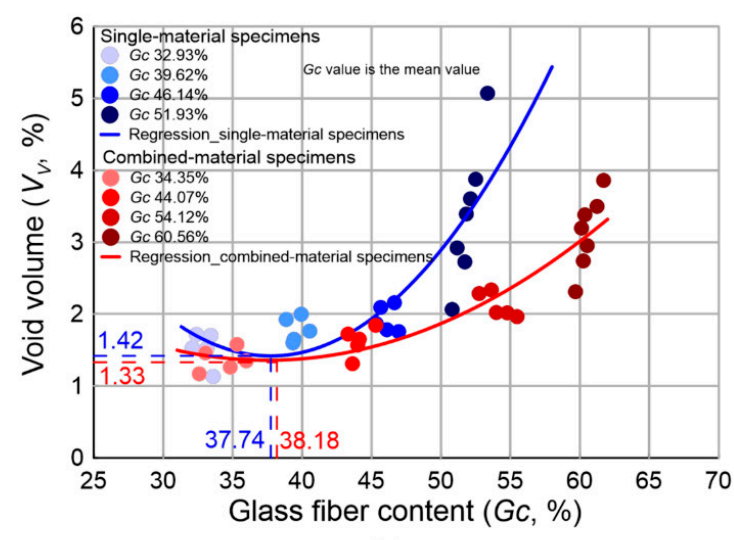

(a)

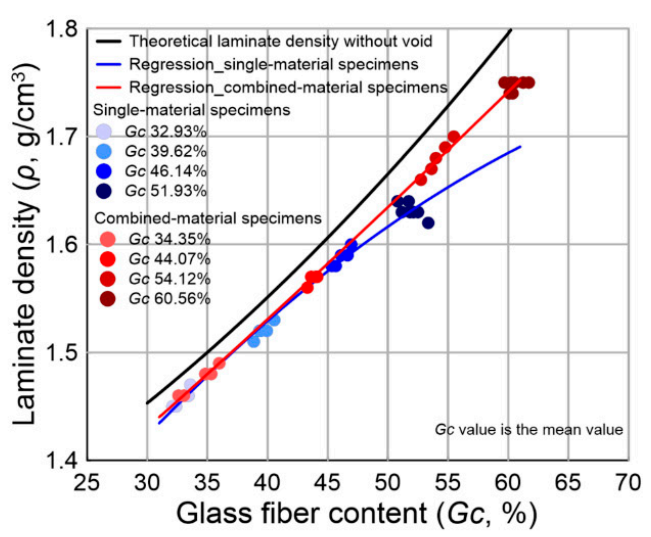

(b)

Figure 9. Variations of the (a) void volume with $G_{C}$, and (b) relative density with $G_{C}$ with consideration of the void volume.

To better understand the cause of the clear difference between the void developments of the two types of specimens with $G_{\mathrm{C}}$, the burn-off test results were divided into a normal $G_{\mathrm{C}}$ area of $30-50 \%$ and a high- $G_{\mathrm{c}}$ area of $>50 \%$ and plotted as violin charts, as shown in Figure 10.

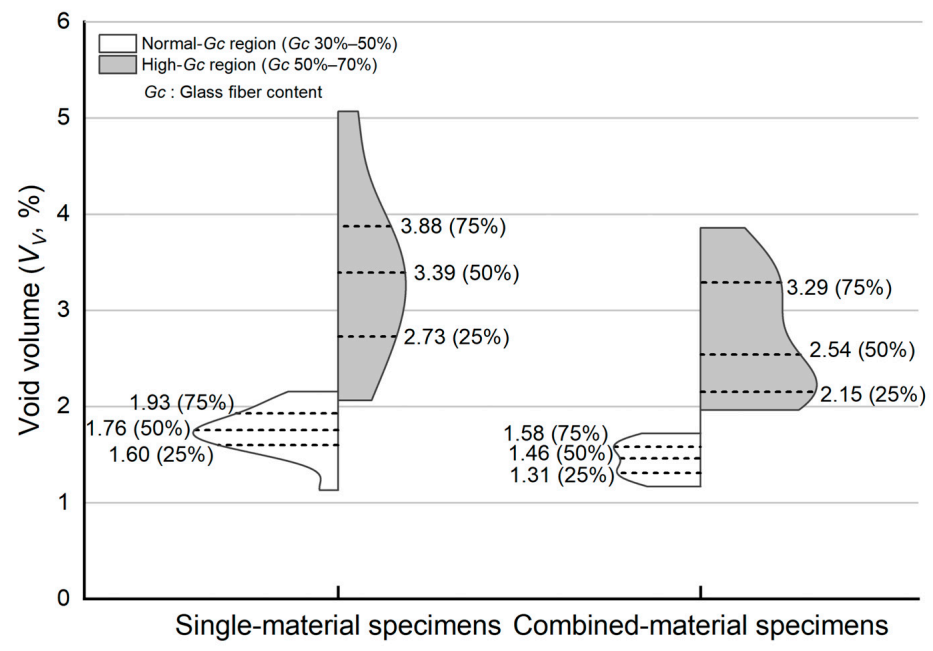

Figure 10. Void volume development in different $G_{\mathrm{C}}$ regions.

In the region of $G_{\mathrm{c}}<50 \%$, both types of specimens exhibit void volume developments of $1-2 \%$, with that of the single-material specimens being slightly larger. This is believed to be the cause of the lower pulse-echo velocity of the single-material specimens for a given 
$G_{\mathrm{c}}$ (Figure 7). In the high- $G_{\mathrm{c}}$ region $(>50 \%)$, the single-material and combined-material specimens exhibit different void volume development trends. The variation of the void volume of the former is widely distributed over $2-5 \%$, with the median value being $3.39 \%$. The variation range for the combined-material specimens is narrower, with a median value of $2.54 \%$. The combination of CSM and WR might have improved the bonding between the laminate layers for a given $G_{c}$ [32], resulting in a higher-quality material. This bonding effect is more evident for high- $G_{\mathcal{C}}$ values.

\section{Conclusions}

The effect of production quality of GFRP laminates on their transmission of ultrasonic waves was investigated. In addition to the glass fiber contents commonly applied to GFRP laminates used to produce ship structures, such as hull plates and decks, CSM and WR fabrics were also combined to achieve $G_{c}$ contents of 30-70\%, such as those used for stiffeners. Ultrasonic NDE was conducted on the laminate specimens.

Overall, the single-material specimens tended to have a lower pulse-echo velocity for a given $G_{c}$ value. The actual relative densities of the CSM-only specimens calculated from the void volumes determined by burn-off tests were found to be lower than the theoretical design values. This was more evident for $G_{c}$ values of $\geq 50 \%$ owing to the increased voids in the laminates, resulting in a decreased ultrasonic velocity. The combined CSM-WR laminates also contained more voids in the higher- $G_{\mathrm{C}}$ region, although the void development was less than that of the CSM-only laminates. The present results indicate that, for a given glass fiber content, the configuration of the fiber reinforcement can be used to prevent the development of voids, thereby improving the quality of the laminates. This is specifically the case for high- $G_{c}$ values compared with the values of $30-50 \%$ commonly used to produce GFRP ship structures. Hence, to achieve more accurate NDE of GFRP structures, it is important to consider not only the relative density but also the glass fiber content and nature of the GFRP fabric.

Author Contributions: Conceptualization and methodology: D.O.; funding acquisition: J.H.W.; specimen preparation: S.-G.L.; testing and investigation: S.-G.L. and D.O.; writing of original manuscript: D.O. and J.H.W.; writing, review, and editing of manuscript: J.H.W. All authors have read and agreed to the published version of the manuscript.

Funding: This work was partly supported by the "Mid-sized Shipyard Dock and Quay Planning Integrated Management System" program of the Republic of Korea Ministry of Trade, Industry, and Energy (grant number 20007834) and the Republic of Korea Ministry of Oceans and Fisheries with the support of the Jeonnam Sea Grant Program (grant number 20170347). The funders had no role in the design of the study; in the collection, analyses, or interpretation of data; in the writing of the manuscript, or in the decision to publish the results.

Institutional Review Board Statement: Not applicable.

Informed Consent Statement: Not applicable.

Data Availability Statement: Not applicable.

Conflicts of Interest: The authors declare no conflict of interest.

\section{References}

1. Shenoi, R.A.; Dulieu-Barton, J.M.; Quinn, S.; Blake, J.I.R.; Boyd, S.W. Composite materials for marine applications: Key challenges for the future. In Composite Materials, 1st ed.; Nicolais, L., Meo, M., Milella, E., Eds.; Springer: London, UK, 2011; pp. 69-89. ISBN 978-0-85729-165-3.

2. Oh, D.K. Marine Composites, FRP Small craft, and Eco-Friendliness. The Society of Naval Architects of Korea Webzine. Available online: http:/ / www.snak.or.kr/newsletter/webzine/news.html?Item=board21\&mode=view\&s_t=1\&No=645 (accessed on 14 December 2020).

3. Kudela, P.; Żak, A.; Krawczuk, M.; Ostachowicz, W. Modelling of wave propagation in composite plates using the time domain spectral element method. J. Sound Vib. 2007, 302, 728-745. [CrossRef]

4. Jeong, S.H.; Woo, J.H.; Oh, D.K. Simulation of greenhouse gas emissions of small ships considering operating conditions for environmental performance evaluation. Int. J. Nav. Archit. Ocean Eng. 2020, 12, 636-643. [CrossRef] 
5. Scott, R.J. Fiberglass Boat Design and Construction, 2nd ed.; The Society of Naval Architects and Marine Engineers: Jersey City, NJ, USA, 1996; p. 21.

6. Cao, M.; Su, Z.; Xu, H.; Radzieński, M.; Xu, M.R.; Ostachowicz, W. A novel damage characterization approach for laminated composites in the absence of material and structural information. Mech. Syst. Signal Process. 2020, 143, 106831. [CrossRef]

7. Sha, G.; Xu, H.; Radzieński, M.; Cao, M.; Ostachowicz, W. Guided wavefield curvature imaging of invisible damage in composite structures. Mech. Syst. Signal Process. 2021, 150, 107240. [CrossRef]

8. Hakim, I.A.; Donaldson, S.L.; Meyendorf, N.G.; Browning, C.E. Porosity effects on interlaminar fracture behavior in carbon fiber-reinforced polymer composites. Mater. Sci. Appl. 2017, 8, 170-187. [CrossRef]

9. Lee, S.G.; Han, Z.Q.; Lee, C.W.; Oh, D.K. Correlation between probe frequency and pulse-echo velocity for ultrasonic testing of a fiber-reinforced plastic hull plate. J. Korean Soc. Mar. Environ. Saf. 2020, 26, 219-226. [CrossRef]

10. Harris, B. Fatigue in Composites, 1st ed.; Woodhead Publishing: Cambridge, UK, 2003; pp. 243-244. ISBN 978-1-85573-608-5.

11. Greene, E. Marine composites non-destructive evaluation. In Proceedings of the SSC Ship Structure Symposium: Vessel Safety \& Longevity through Ship Structure Research, Linthicum Heights, MD, USA, 18-20 May 2014.

12. Kudela, P.; Wandowski, T.; Malinowski, P.; Ostachowicz, W. Application of scanning laser dopper vibrometry for delamination detection in composite structures. Opt. Lasers Eng. 2017, 99, 46-57. [CrossRef]

13. Mouritz, A.P. Ultrasonic and interlaminar properties of highly porous composites. J. Compos. Mater. 2000, 34, 218-239. [CrossRef]

14. Oh, D.K.; Han, Z.Q.; Noh, J.K.; Jeong, S.H. Laminate weight optimization of composite ship structures based on experimental data. J. Soc. Nav. Archit. Korea 2020, 57, 104-113. [CrossRef]

15. Han, Z.Q.; Jeong, S.H.; Noh, J.K.; Oh, D.K. Comparative study of glass fiber content measurement methods for inspecting fabrication quality of composite ship structures. Appl. Sci. 2020, 10, 5130. [CrossRef]

16. Wróbel, G.; Pawlak, S. A comparison study of the pulse-echo and through-transmission ultrasonics in glass/epoxy composites. J. Achiev. Mater. Manuf. Eng. 2007, 22, 51-54.

17. Botelho, E.C.; Figiel, L.; Rezende, M.C.; Lauke, B. Mechanical behavior of carbon fiber reinforced polyamide composites. Compos. Sci. Technol. 2003, 63, 1843-1855. [CrossRef]

18. Dong, Y.; Ansari, F. Non-destructive testing and evaluation (NDT/NDE) of civil structures rehabilitated using fiber reinforced polymer (FRP) composites. In Service Life Estimation and Extension of Civil Engineering Structures, 1st ed.; Karbhari, V.M., Lee, L.S., Eds.; Woodhead Publishing: Cambridge, UK, 2011; pp. 193-222. ISBN 978-1-84569-398-5.

19. Mohamed, A.; Thameur, M.; Chedly, A. Ultrasonic velocity as a tool for physical and mechanical parameters prediction within geo-materials: Application on cement mortar. Russ. J. Nondestr. Test 2018, 54, 345-355. [CrossRef]

20. Ibrahim, M.E. Nondestructive testing and structural health monitoring of marine composite structures. In Marine Applications of Advanced Fiber-Reinforced Composite; Graham-Jones, J., Summerscales, J., Eds.; Woodhead Publishing: Cambridge, UK, 2016; pp. 147-183. ISBN 978-1-78242-250-1.

21. Lee, S.G.; Oh, D.K.; Woo, J.H. Experimental study on the characteristics of the change in glass-fiber weight content in ultrasonic inspection of GFRP hull structures. In Proceedings of the 2020 General Meeting \& Annual Autumn Conference of The Society of Naval Architects of Korea, Changwon, Korea, 5-6 November 2020.

22. Kenderian, S.; Esquivel, O.; Olson, K.R.; Johnson, E.C. A general overview of some nondestructive evaluation (NDE) techniques for materials characterization. Proc. Opt. Mater. Struct. Technol. IV SPIE 2009, 7425. [CrossRef]

23. American Society for Testing and Materials. Standard Practice for Ultrasonics Velocity in Materials (ASTM E494-15); ASTM International: West Conshohocken, PA, USA, 2015.

24. Fahad, B.M.; Naser, A.A. Enhance some insulation properties of epoxy by using waste materials. Al Nahrain J. Eng. Sci. 2018, 21, 259-265. [CrossRef]

25. Lee, J.; Soutis, C. Thickness effect on the compressive strength of T800/924C carbon fiber-epoxy laminates. Compos. Part A Appl. Sci. Manuf. 2005, 36, 213-227. [CrossRef]

26. Skain, R.; Ay, I.; Yaman, R. An investigation of bending fatigue behavior for glass-fiber reinforced polyester composite materials. Mater. Des. 2008, 29, 212-217. [CrossRef]

27. Owens Corning. Available online: http://www.owenscorning.co.kr/reinforcements.asp (accessed on 14 December 2020).

28. Aekyung Chemical Co., Ltd. Available online: https://www.akc.co.kr/product/list.do?bcode_id=BCK1\&mcode_id=BCK1_1 \&scode_id=BCK1_1_3 (accessed on 14 December 2020).

29. American Society for Testing and Materials. Test Methods for Constituent Content of Composite Materials (ASTM D3171-15); ASTM International: West Conshohocken, PA, USA, 2015.

30. Mouritz, A.P.; Townsend, C.; Shah Khan, M.Z. Non-destructive detection of fatigue damage in thick composites by pulse-echo ultrasonics. Compos. Sci. Tech. 2000, 60, 23-32. [CrossRef]

31. Dakota Ultrasonics. Available online: https://dakotaultrasonics.com/product/corrosion/cmx-dl-plus/ (accessed on 14 December 2020).

32. Heckadka, S.S.; Nayak, S.Y.; Narang, K.; Pant, K.V. Chopped strand/plain weave E-glass as reinforcement in vacuum bagged epoxy composites. J. Mater. 2015, 2015, 1-7. [CrossRef] 